\title{
Bibliometric Analysis of Clinical Decision Support Systems
}

\author{
Cemal Aktürk \\ 192180 street, 27010 Şahinbey/Gaziantep, Turkey \\ Corresponding author: Cemal Aktürk (cemalakturk79@gmail.com)
}

Faculty of Engineering and Natural Sciences, Gaziantep Islam Science and Technology University, Beştepe neighbourhood,

\begin{abstract}
Clinical decision support systems are computer systems that help decision-makers make effective and efficient decisions in the diagnosis and treatment of diseases, patient care, and health institution management. In this study, descriptive and bibliometric analyses were carried out of studies on clinical decision support systems conducted between 2016 and 2021 in journals included in the Web of Science database. In the first stage, the distribution of the articles was determined according to the publication year, country, institution, journal and citation numbers within the scope of descriptive analysis. In the second stage, within the scope of bibliometric analysis, co-author-institution, co-citation-author, cocitation-country and common keyword analysis of the articles were made. As a result of the research, 8052 articles on clinical decision support systems were reached. It was observed that the country with the most studies on this subject are the United States and the institution is Harvard University. It was seen that the journal with the highest number of articles was PLoS ONE. In addition, co-citations, institutional and country collaborations between authors are presented with visual maps. The purpose of this study is to present the studies on clinical decision support systems in a systematic framework and to provide a broad perspective to the researchers and field experts working on this subject.
\end{abstract}

\section{Keywords}

Bibliometric analysis, Bibliometrics, Clinical decision support system, Decision making, Scientific collaboration. 


\section{Introduction}

Decision support systems are computer-based systems that help people make efficient decisions when solving complex problems. These systems offer possible alternative solutions to the user as decision support by defining the problem with certain criteria and using various models and analysis approaches. The inability to define problems correctly and the high number of potential solutions increases the complexity of the decision-making process and increases the need for decision support systems in this regard. Today, the use of decision support systems is becoming widespread in all areas of life.

Clinical decision support systems (CDSS) provide patient-specific decision support to physicians in the diagnosis and treatment of diseases, and to nurses in providing health services and patient follow-up. CDSSs not only support decision-making regarding patients and diseases, but they also support financial decision-making in the management of a healthcare facility. Therefore, CDSS is a field of study that is directly related to the branches of science such as medicine, informatics, pharmacy, and management. CDSSs are computer systems that create stimulating and directive output by processing the health data of patients, making it easier to carry out correct medical procedures, and provide quality health services to patients (Yilmaz \& Özdemir, 2017). These systems include prescriptions, drug dose calculations, patient-disease data, and some related automatic alert/reminder functions (Bright et al., 2012). The input of the CDSS is a knowledge base of medical expertise and patient data, while its output is the diagnosis of the disease or potential decisions for treatment. The purpose of CDSS is not to replace physicians, but to help healthcare professionals make the right decisions by handling increasing medical data and eliminating confusion created by the size of this data (Özata \& Aslan, 2004). CCDS accelerates and facilitates correct diagnosis and treatment process of the disease, while reducing prescription medication errors and medical costs, ensuring a better quality of patient care services (Bright et al., 2012). CDSSs are categorized according to purpose and function as follows (Ylldiz et al., 2020; Wright et al., 2011):

- Drug dose calculation systems (systems that help calculate the appropriate drug dose according to the patient's height, weight, age, and liver-kidney functions),

- Order facilitators,

- Alerts and reminders,

- Monitoring systems,

- Expert systems,

- Workflow support systems.

In this study, a bibliometric analysis of studies on CDSS is presented. Bibliometric analysis methods aim to reveal the citation relationship between the publications of researchers in a particular field of science (Börner et al., 2005). Methods such as co-author analysis, co-citation analysis, most cited texts, and common keyword analysis on a research topic are frequently used in bibliometric analysis studies. The data obtained with these methods are also visualized through various mapping programs (Gülmez et al., 2021). With the help of maps, publications, authors and keywords, relations and cooperation networks between institutions and countries are visualized, and the information is presented to researchers in a more understandable way.

This section continues with a literature review and the purpose and importance of the study. This paper is organized as follows. Section 2 describes the methodology of the study, which consists of data collection and data analysis. Section 3 describes the findings of the research questions. Finally, Section 4 presents the conclusion and discussion part of the study. 


\subsection{Literature Review}

The bibliometric analysis method is a useful method that provides a systematic presentation of the studies in a particular field or subject with visual maps and provides a holistic view of the subject. Bibliometric analysis methods are used in this article and current studies using these methods are included here.

First of all, bibliometric studies in different fields were examined. Merigó and Yang (2017) conducted a bibliometric analysis of studies published in the Web of Science (WoS) database in the last decade on business and management research. Agbo et al. (2021a) presented the trend and thematic focus on smart learning environments by conducting a bibliometric analysis of articles published in journals in the Scopus database. Agbo et al. (2021b) made content and bibliometric analyses of studies on the use of virtual reality in computer science education in another study. Saqr et al. (2021) carried out the bibliometric analysis of 1,874 documents on computational thinking from the Scopus database. Gil et al. (2020) conducted a bibliometric analysis study on decision support systems related to accident prevention of ships in face of the increasing traffic density in maritime transport. By analyzing 107 studies on this topic, which they obtained from the WoS database, the researchers revealed the network of relationships between authors, countries, and studies. Kitsios et al. (2020) presented a bibliometric analysis of 72 studies on strategic management, corporate sustainability, and decision-making. Minhas and Potdar (2020) conducted a bibliometric analysis of the studies published between 2000 and 2016 on WoS and Scopus databases on decision support systems used in construction projects. Sweileh et al. (2017) conducted a bibliometric analysis of 5,465 studies on the use of mobile technologies in healthcare between 2006 and 2016. Chen et al. (2018) conducted a bibliometric analysis of 1,405 studies in natural language processing and medicine between 2007 and 2016.

As a result of their bibliometric analysis of the 100 most cited articles in the field of medical informatics, Nadri et al. (2017) stated that clinical decision-making took the second place in studies conducted until 2016. Jalali et al. (2019) conducted a bibliometric analysis of 472 articles on cybersecurity and healthcare services published in PubMed and WoS in the last decade. Santos et al. (2019) conducted a bibliometric analysis of the studies published in WoS, Scopus, and Science Direct databases between 2009 and 2018, using data mining and machine learning techniques in health problems, and created a collaboration map of 250 articles in this field. Hu et al. (2020) examined 1,575 studies in the WoS database with bibliometric analysis, which included medical data mining research. Guo et al. (2020) conducted a bibliometric analysis of studies on artificial intelligence in healthcare services. The researchers examined a total of 5,235 studies conducted until 2019. Diaby et al. (2013) carried out a bibliometric analysis research covering the studies conducted between 1960 and 2011 on multi-criteria decision analysis in healthcare services. Adunlin et al. (2015) executed a bibliometric analysis of the studies carried out in the same field between 1980 and 2013.

Considering the studies on clinical decision support systems from the past to the present, it can be seen that the number of bibliometric analysis studies conducted in this field is limited. For this reason, in this section, bibliometric analysis studies conducted in different fields in the literature are mentioned and those related to medical and health services are presented.

\subsection{Purpose and Importance of the Study}

The aim of this research is to reveal new trends in CDSS in the light of the information obtained by identifying the most relevant and effective research and scientific networks on CDSS. Thus, it aims to contribute to a better understanding of the structure and content of the academic field on CDSS.

The research questions of the study are listed below.

1. What is the distribution of the publications on clinical decision support systems by year?

2. What is the distribution of the publications on clinical decision support systems by country? 
3. What is the distribution of the publications on clinical decision support systems according to institutions?

4. What is the distribution of the publications on clinical decision support systems according to journals?

5. What are the most cited publications on clinical decision support systems?

6. What is the co-author-institution network of the publications on clinical decision support systems?

7. What is the co-citation-author network of the publications on clinical decision support systems?

8. What is the co-citation-country network of the publications on clinical decision support systems?

9. What are the common keywords of the publications on clinical decision support systems?

10. What is the thematic future outlook of the CDSS field?

\section{Method}

\subsection{Data Collection}

In this study, international publications obtained in accordance with the search criteria on clinical decision support systems on the WoS database were analyzed using the bibliometric analysis method. WoS was chosen because it has high quality and influential scientific articles, abstracts, references, and is a widely accepted data source worldwide (Gil et al, 2020; Li \& Hale, 2016; van Nunen et al., 2018). Since journals are also scanned in other databases, the repetition of the same articles and authors from different sources was prevented by choosing WoS as a data source. Thus, the research aimed to reach more distinguished articles. In order to determine the search word, a general research was conducted on clinical decision support. Since the expressions "clinical decision support" and "clinical decision making" are generally used in the titles and keywords of the studies in the literature, "clinical decision support" OR "clinical decision making" was determined as a search word.

The search results were filtered again according to the publication year, publication language, publication type, and scanned index criteria. Studies between 2016 and 2021 were selected as the publication year in order to reach the studies conducted in the last five years. The studies were filtered for English as the language and article as the type of the study. In addition, the results were narrowed down to the studies that had been scanned in Science Citation Index and Social Science Citation Index (WoS). As a result, 8,052 articles that met these criteria were reached as of March 25, 2021. All the data for these articles were saved in 17 files, which were obtained from the WoS interface, with a maximum of 500 recordings in each.

\subsection{Data Analysis}

The analysis of the data was carried out in two stages. In the first stage, the distributions of the publications from the WoS database by year, country, institution, and source were obtained by the descriptive analysis method. Afterwards, 17 data files recorded for 8,052 articles were transferred to the VOSviewer program, and bibliometric analyses were carried out. In this context, co-author institution analysis, co-author citation analysis, co-author country analysis, and common keyword analysis were performed. Before the analyses, the data were examined with the VOSviewer program and the keyword, author, and country names written in different characters were rearranged.

\section{Findings}

\subsection{Distribution of the Publications by Year}

The distribution of the publications by year is given in Table 1 and Figure 1. Accordingly, approximately one fourth of the total of 8,052 articles obtained were published in 2020 ( $n=2,114,26 \%$ ). It can be seen in Table 1 and Figure 1 that the number of publications increased with each passing year. On the other hand, 
only the first quarter of 2021 had passed at the time the data was collected in the study. This is the reason why the number of studies in 2021 is lower.

Table1. Distribution of Publications by Year (2016-Q1/2021).

\begin{tabular}{lll}
\hline Publication Years & N & $\%$ \\
\hline 2021 (first quarter) & 379 & 4.70 \\
2020 & 2114 & 26.25 \\
2019 & 1735 & 21.54 \\
2018 & 1416 & 17.58 \\
2017 & 1260 & 15.64 \\
2016 & 1148 & 14.25 \\
\hline SUM & 8052 & 100 \\
\hline
\end{tabular}

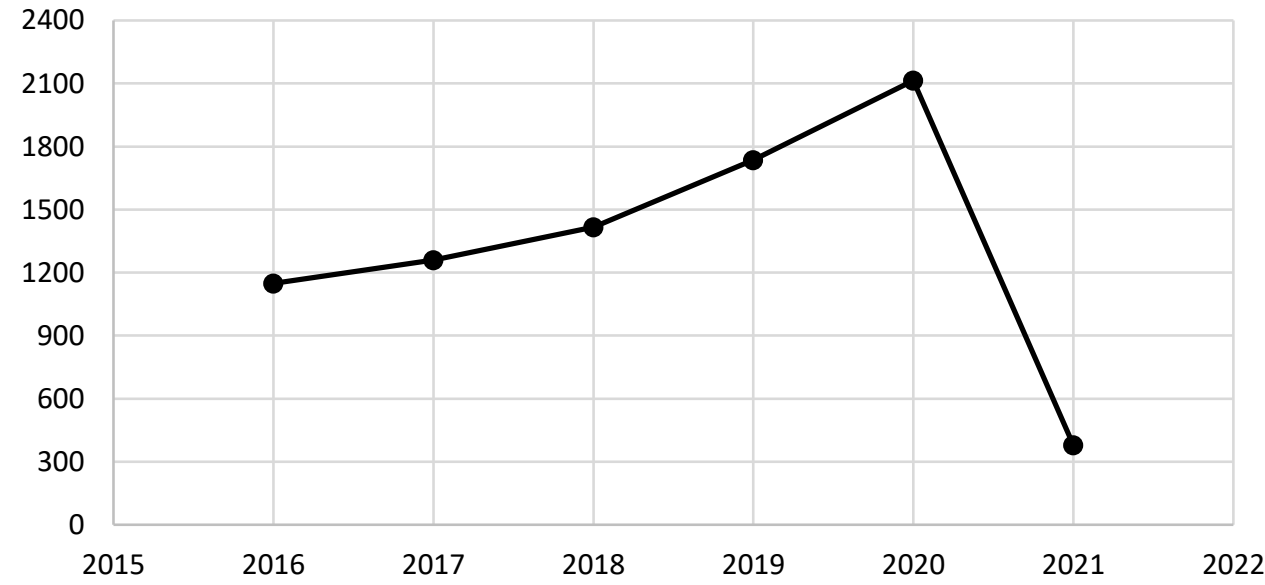

Figure 1. Distribution of Publications by Year (2016 - Q1/2021).

\subsection{Distribution of the Publications by Country}

The 10 countries with the highest number of publications in the distribution of the publications by country are shown in Table 2. The country with the most research and publication studies on clinical decision support systems and clinical decision making is the United States of America ( $n=3,847)$. It can be seen that USA is the country with almost half of the studies in this field. The USA is followed by the UK with 920 studies and by China with 707 studies. The country that ranked 10th is Switzerland $(n=273)$. 
Table 2. Distribution of Publications by Country

\begin{tabular}{llll}
\hline No & Countries/Regions & N & \% \\
\hline 1 & USA & 3847 & 47.77 \\
2 & UK & 920 & 11.42 \\
3 & China & 707 & 8.78 \\
4 & Canada & 624 & 7.75 \\
5 & Netherlands & 596 & 7.40 \\
6 & Germany & 580 & 7.20 \\
7 & Australia & 562 & 6.98 \\
8 & Italy & 397 & 4.93 \\
9 & Spain & 293 & 3.64 \\
10 & Switzerland & 273 & 3.40 \\
\hline
\end{tabular}

\subsection{Distribution of the Publications by Institution}

The 10 institutions that have the most studies in the distribution of studies by author institution are given in Table 3. It can be seen that the institution that publishes the most is Harvard University $(n=546)$. Harvard University is followed by the University of California and Harvard Medical School. Even the University of Toronto, which produced the lowest number of publications, as seen in Table 3, has 202 studies.

Table 3. Distribution of Publications by Institution.

\begin{tabular}{llll}
\hline No & Organizations-Enhanced & n & \% \\
\hline 1 & Harvard University & 546 & 6.781 \\
2 & University of California & 385 & 4.781 \\
3 & Harvard Medical School & 331 & 4.111 \\
4 & University of London & 270 & 3.353 \\
5 & University of Texas & 236 & 2.931 \\
6 & Brigham and Women's Hospital & 226 & 2.807 \\
7 & U.S. Department of Veterans Affairs & 223 & 2.769 \\
8 & Veterans Health Administration & 212 & 2.633 \\
9 & Johns Hopkins University & 207 & 2.571 \\
10 & University of Toronto & 202 & 2.509 \\
\hline
\end{tabular}

\subsection{Distribution of the Publications by Journals}

Table 4 shows the distribution of the studies by journal. In this context, it can be seen that 167 studies were published in the journal PLoS ONE. More than 100 studies on clinical decision support systems were published in the journals Journal of the American Medical Informatics Association, Applied Clinical Informatics, and BMC Medical Informatics and Decision Making. When the number of citations per article of journals were analyzed, it was seen that the highest rate belonged to the journal Scientific Reports, 
which ranks 4th according to the number of publications (14.53). The American Journal of Transplantation is in the second place with 13.98, and the Journal of the American Medical Informatics Association is in the third place with 10.53. The average number of citations per article of 15 journals with the highest number of publications was calculated as 7.15. It is noteworthy that the PLoS ONE journal, which ranks first in terms of the number of publications, is below this average. It can be seen in Table 4 that the journals publish in fields such as medicine, informatics, decision-making, artificial intelligence, and electrical and electronic engineering.

Table 4. Distribution of Publications by Journals.

\begin{tabular}{lllll}
\hline No & Source Titles & Publications & Citations & $\begin{array}{l}\text { Num. of } \\
\text { Citations per } \\
\text { Article }\end{array}$ \\
\hline 1 & PLoS ONE & & 7.04 \\
2 & Journal of the American Medical Informatics Association & 114 & 1176 & 1200 \\
3 & Applied Clinical Informatics & 112 & 451 & 4.03 \\
4 & BMC Medical Informatics and Decision Making & 104 & 495 & 4.76 \\
5 & Scientific Reports & 87 & 1264 & 14.53 \\
6 & BMJ Open & 84 & 545 & 6.49 \\
7 & International Journal of Medical Informatics & 76 & 576 & 7.58 \\
8 & American Journal of Transplantation & 61 & 853 & 13.98 \\
9 & Journal of Biomedical Informatics & 51 & 354 & 6.94 \\
10 & JMIR Medical Informatics & 49 & 238 & 4.86 \\
11 & IEEE Access & 48 & 225 & 4.69 \\
12 & Journal of Medical Internet Research & 45 & 147 & 3.27 \\
13 & Artificial Intelligence in Medicine & 39 & 263 & 6.74 \\
14 & Health Informatics Journal & 39 & 137 & 3.51 \\
15 & BMC Cancer & 37 & 307 & 8.30 \\
\hline & & & & \\
\hline
\end{tabular}

\subsection{Most Cited Articles}

The 10 most cited studies among the articles included in the study are listed in Table 5 according to number of citations. The most cited article among the publications scanned within the scope of the research has 4,600 citations and was published in the Thyroid journal. The article that ranked second received 1,864 citations and was published in the Radiology journal. The articles in Table 5 are generally about hormones, cancer, and immune diseases, and image processing and deep learning techniques are used in the studies. 
Table 5. Top 10 Most cited articles.

\begin{tabular}{llc}
\hline No & Articles & Citations \\
\hline 1 & Haugen et al., 2016 & 4600 \\
2 & Gillies et al., 2016 & 1864 \\
3 & McCrindle et al., 2017 & 736 \\
4 & Alexander et al., 2017 & 636 \\
5 & Kermany et al., 2018 & 608 \\
6 & Puzanov et al., 2017 & 589 \\
7 & Park et al., 2016 & 521 \\
8 & Jellinger et al., 2017 & 452 \\
9 & Costa et al., 2017 & 389 \\
10 & Miotto et al., 2016 & 354
\end{tabular}

\subsection{Co-Author - Institution Analysis}

The relationships between the institutions where the co-authors in the studies examined in the research work are given in the visual in Figure 2 obtained from the VOSviewer program. During the analysis, institutions with at least 40 articles were selected, and a total of 96 institutions was reached. In Figure 2, it can be seen that institutions with the same color code are in cooperation with each other, and Harvard Medical School has the highest number of collaborations. Institutions in the USA are often at the center of the collaboration.

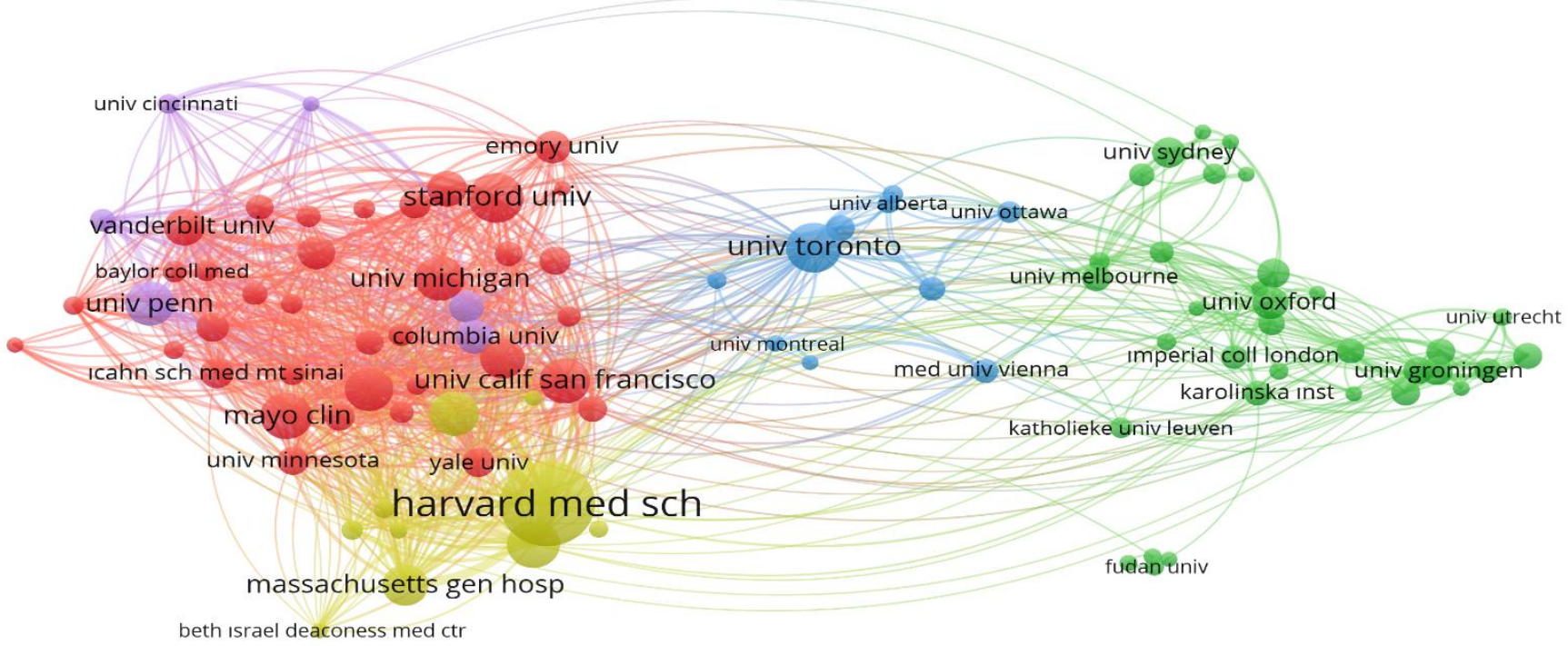

Figure 2. Collaborations between Co-Authors' Institutions.

\subsection{Co-Citation - Author Analysis}

Analyzing the common citations showed that a total number of 158,137 authors were cited in the studies. When at least 50 citations were used as the categorization number, 137 authors were obtained. The cocitation relationship of the authors is shown in Figure 3. When Figure 3 is examined, World Health Organization can be seen as the co-author with the most citations. The number of citations received by the 
institution was calculated to be 463. This is followed by authors named "Bates, D. W." with 329 citations and "Centers for Disease Control" with 243 citations. Authors who received many citations together are shown in the same clusters with the same color code. The largest and most prominent clusters are those in green, red, and blue, respectively.

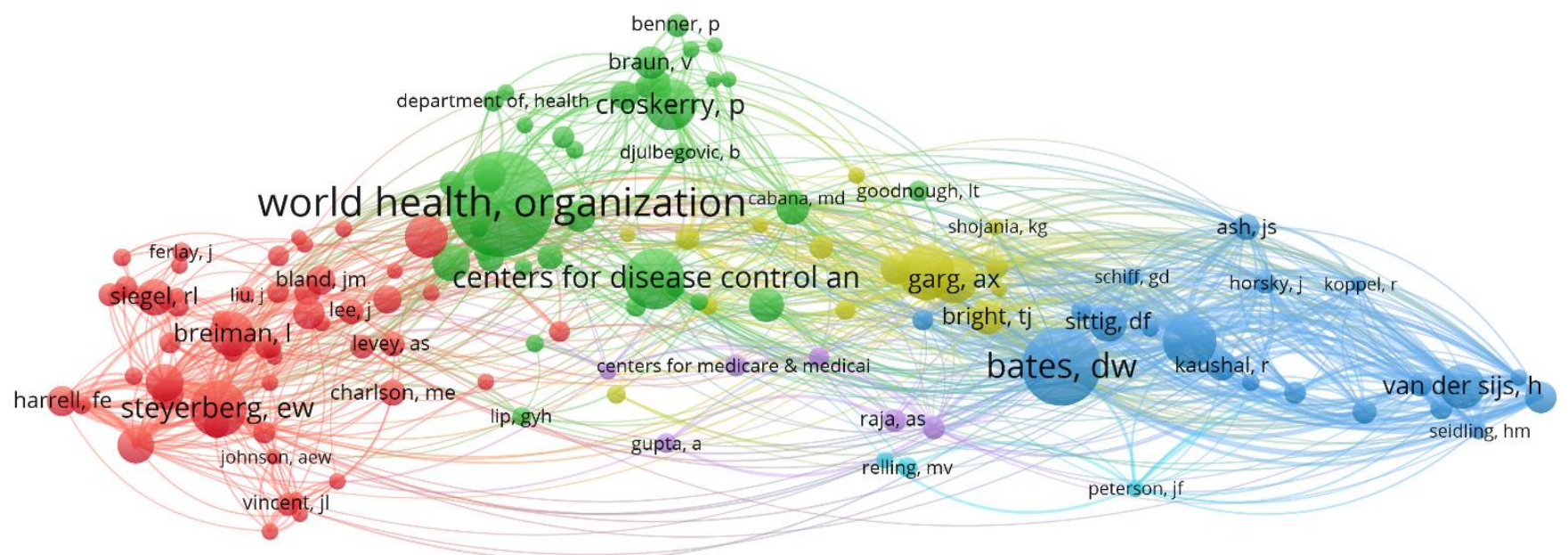

Figure 3. Co-Author Citation Network.

\subsection{Co-Citation - Country Analysis}

Analyzing the citation relationship between countries shows that there are studies from a total of 120 countries. When the countries with at least 10 citations are categorized, the citation relationship of 61 countries is shown in Figure 4. The most cited countries were the USA $(\mathrm{n}=44,683)$, Canada $(\mathrm{n}=11,609)$, UK/England $(n=10,935)$, Italy $(n=10,283)$, and France $(n=8,870)$, respectively. 


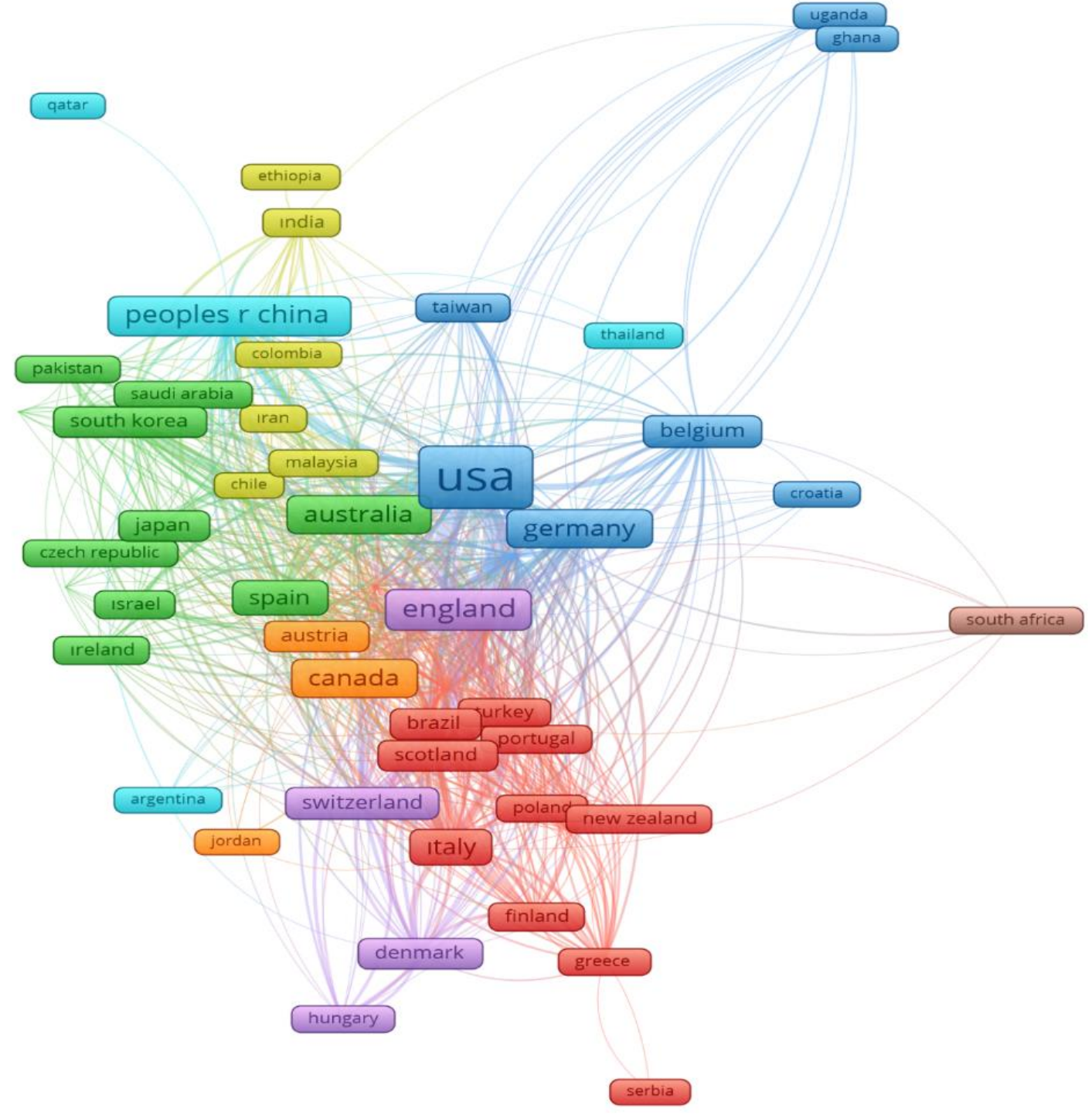

Figure 4. Co-citation analysis - Countries Network Map.

\subsection{Common Keywords Analysis}

Analyzing the keywords used in the studies showed that a total number of 15,782 keywords were used. When the minimum of 10 repetitions of a word was taken as a criterion, 392 keywords categorized according to this distinction were reached. As the number of repetitions increases, the number of keywords subject to categorization naturally decreases. The common words obtained as a result of the analysis are shown in Figure 5. When Figure 5 is examined, it reveals that the most repeated keywords are "clinical decision support" (492 times), "clinical decision-making" (462 times), and "machine learning" (268 times), respectively. Since the research covers many fields such as medicine, informatics, and pharmacy, this situation is also reflected in common word analysis. There is a wide range of research topics, disease and drug names, and scientific methods belonging to these fields, as shown in Figure 5. Word groups are represented by clusters with different color codes, such as green, yellow, red, and blue. The relationship between colors and words is formed according to the number of times they are used together and the number of repetitions. 


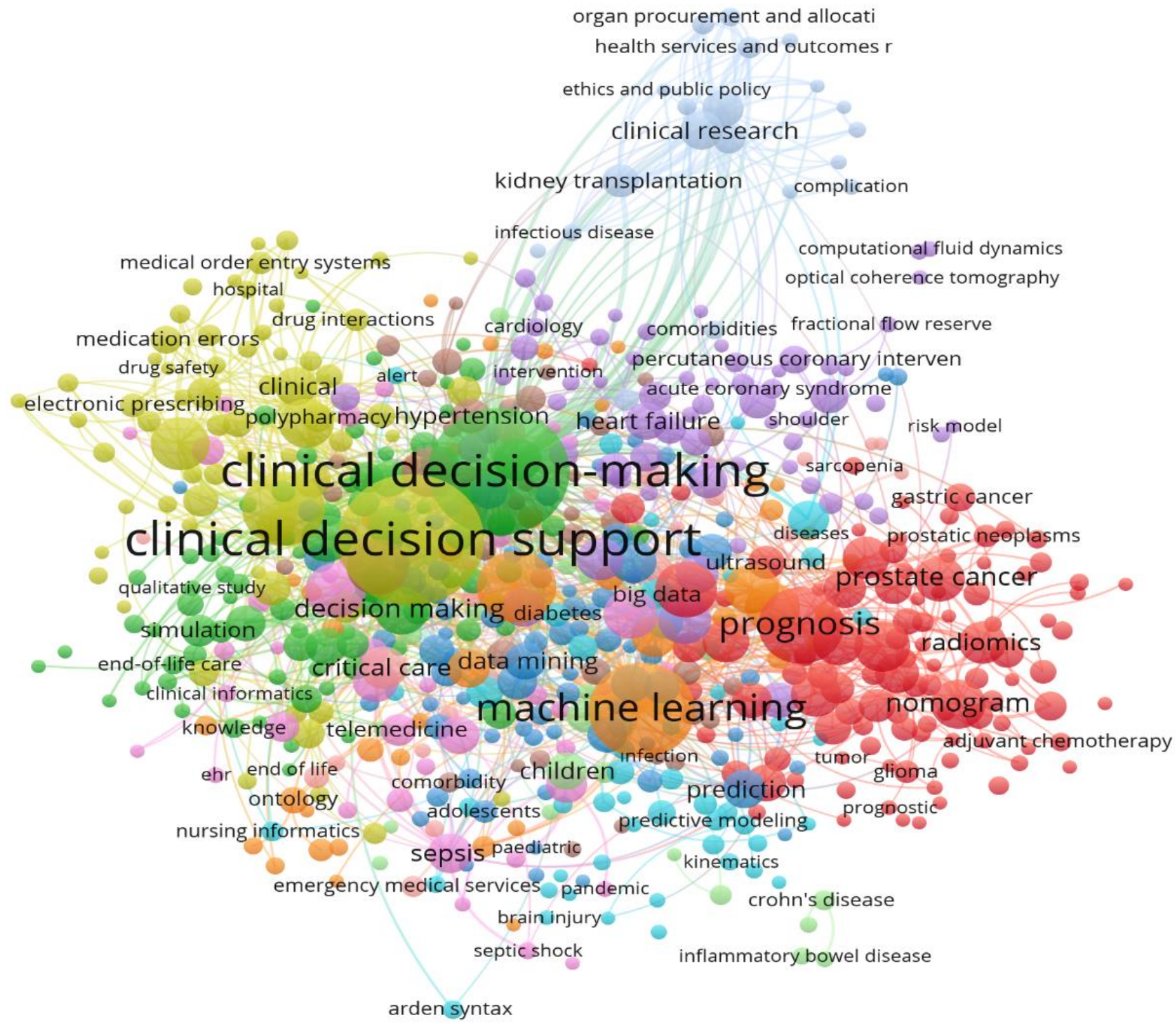

Figure 5. Visual Map of Common Keywords.

\subsection{Thematic Future Outlook of the CDSS}

In the light of the findings obtained from the study, it can be observed that diagnosing diseases by image processing is one of the most cited topics and the most interesting issue for researchers. In addition, it shows that researchers mostly focus on the diagnosis of tumors, cancer and endocrine diseases. This situation is an indication of the indispensable place of deep learning studies on the basis of image processing in the future of CDSS. It can also be said that the diagnosis of diseases such as cancer and Covid-19 with deep learning methods will continue to attract attention in the future.

\section{Discussion and Conclusion}

In this study, descriptive and bibliometric analysis of clinical decision support systems was conducted by examining the studies published in journals scanned on WoS. Examining the findings obtained from the research reveals that research and article studies on clinical decision support systems have been continuously increasing since 2016. The year with the highest increase in the number of studies was 2020. As the institution and country where the most publications are made, the USA and institutions in the USA rank first regarding research on clinical decision support systems. On the other hand, the PLoS ONE journal, which hosts the most publications, is a USA- and UK-based magazine. Examining the journals in 
which the most articles are published on this subject shows that articles from the relevant journals are also cited a lot. Among these journals, the most cited journal is Scientific Reports, which ranks fifth.

The fact that these journals around the world publish so many articles on clinical decision support systems is not a coincidence; it is because they generally include high quality and innovative studies (which can be understood from the total number of citations of the journals). When we look at the countries where the most articles on clinical decision support systems are published, we can see that all of them have developed and strong economies. It can be argued that the reason why developing and underdeveloped countries rank low in this ranking are the limitations of researchers, such as insufficient foreign language knowledge, excessive academic course load, and inadequate project grant support. At the same time, the difference in the number of journals scanned on WoS belonging to the countries can be considered a reason for this situation. As a solution to all these, as Gülmez et al. (2019) emphasized in their bibliometric analysis study on education, developing countries should encourage more research by making strategic decisions to increase the quality of their publications and journals.

Examining the most cited studies on clinical decision support systems shows that these are generally articles on image processing and cancer disease. It can be said that the interest in diagnosing diseases will continue by evaluating the data obtained by radiological imaging techniques with image processing methods, as it is also used in the diagnosis of the coronavirus disease (Covid-19), which affected the whole world in late 2019. Such studies also produce very effective results in making clinical decisions. Examining the most repeated keywords obtained in common word analysis shows that words such as "clinical decision support systems," "clinical decision making," "machine learning," "decision making," and "big data" are frequently repeated. This analysis reveals that the research was conducted with the appropriate criteria.

Minhas and Potdar (2020) conducted a bibliometric analysis of the studies published between 2000 and 2016 on WoS and Scopus databases on decision support systems used in construction projects. The top ten countries according to the results of this study are very similar to the top ten countries found in the study of Minhas and Potdar (2020). In addition, the researchers graphically compared the Scopus and WoS citation numbers of the articles they examined in their study and stated that the two databases are similar in citation distribution. In parallel, studies in journals scanned on WoS were taken as a basis, considering that the number of studies on clinical decision support systems is large, and more consistent results would be achieved due to the fact that journals on the WoS database are more selective. The fact that the most publications are produced by the USA in the research results is also compatible with the results of Diaby et al. (2013), Adunlin et al. (2015), and Chen et al. (2018). In addition, in studies on decision analysis in health services, Diaby et al. (2013) stated that articles under the "medical decision making" subtitle took the second place in terms of the number of studies. Adulin et al. (2015) stated that there was an increase in the number of studies towards 2012 and that the most published articles were about medical decision making. The findings of both studies are consistent with this study in terms of increased interest in clinical decision making. This indicates that researchers and experts will continue to show interest in clinical decision support systems in the near future. Guo et al. (2020) examined 5,235 studies covering all studies conducted with artificial intelligence in healthcare services until 2019. In our study, although only the studies conducted in the last five years were selected, 8,052 articles were analyzed, which is almost $50 \%$ more compared to these researchers. Furthermore, this may indicate that decision support systems in the field of healthcare are attracting more attention as a research topic than artificial intelligence studies in the same field. Adunlin et al. (2015) stated that decision-making studies in the field of healthcare were mostly related to cancer disease, which is in accordance with the results of our study. 


\section{Additional Information and Declarations}

Conflict of Interests: The author declares no conflict of interest.

Data Availability: The data that support the findings of this study are available from the corresponding author.

\section{References}

Adunlin, G., Diaby, V., \& Xiao, H. (2015). Application of multicriteria decision analysis in health care: a systematic review and bibliometric analysis. Health Expectations, 18(6), 1894-1905. https://doi.org/10.1111/hex.12287

Agbo, F. J., Oyelere, S. S., Suhonen, J., \& Tukiainen, M. (2021a). Scientific production and thematic breakthroughs in smart learning environments: a bibliometric analysis. Smart Learning Environments, 8(1). https://doi.org/10.1186/s40561-02000145-4

Agbo, F. J., Sanusi, I. T., Oyelere, S. S., \& Suhonen, J. (2021b). Application of Virtual Reality in Computer Science Education: A Systemic Review Based on Bibliometric and Content Analysis Methods. Education Sciences, $11(3), 142$. https://doi.org/10.3390/educsci11030142

Alexander, E. K., Pearce, E. N., Brent, G. A., Brown, R. S., Chen, H., Dosiou, C., Grobman, W. A., Laurberg, P., Lazarus, J. H., Mandel, S. J., Peeters, R. P., \& Sullivan, S. (2017). 2017 Guidelines of the American Thyroid Association for the Diagnosis and Management of Thyroid Disease During Pregnancy and the Postpartum. Thyroid, 27(3), 315-389. https://doi.org/10.1089/thy.2016.0457

Börner, K., Chen, C., \& Boyack, K. W. (2005). Visualizing knowledge domains. Annual Review of Information Science and Technology, 37(1), 179-255. https://doi.org/10.1002/aris.1440370106

Bright, T. J., Wong, A., Dhurjati, R., Bristow, E., Bastian, L., Coeytaux, R. R., Samsa, G., Hasselblad, V., Williams, J. W., Musty, M. D., Wing, L., Kendrick, A. S., Sanders, G. D., \& Lobach, D. (2012). Effect of Clinical Decision-Support Systems. Annals of Internal Medicine, 157(1), 29. https://doi.org/10.7326/0003-4819-157-1-201207030-00450

Chen, X., Xie, H., Wang, F. L., Liu, Z., Xu, J., \& Hao, T. (2018). A bibliometric analysis of natural language processing in medical research. BMC Medical Informatics and Decision Making, 18(S1). https://doi.org/10.1186/s12911-018-0594-x

Costa, F., van Klaveren, D., James, S., Heg, D., Räber, L., Feres, F., Pilgrim, T., Hong, M.-K., Kim, H.-S., Colombo, A., Steg, P. G., Zanchin, T., Palmerini, T., Wallentin, L., Bhatt, D. L., Stone, G. W., Windecker, S., Steyerberg, E. W., \& Valgimigli, M. (2017). Derivation and validation of the predicting bleeding complications in patients undergoing stent implantation and subsequent dual antiplatelet therapy (PRECISE-DAPT) score: a pooled analysis of individual-patient datasets from clinical trials. The Lancet, 389(10073), 1025-1034. https://doi.org/10.1016/s0140-6736(17)30397-5

Diaby, V., Campbell, K., \& Goeree, R. (2013). Multi-criteria decision analysis (MCDA) in health care: A bibliometric analysis. Operations Research for Health Care, 2(1-2), 20-24. https://doi.org/10.1016/j.orhc.2013.03.001

Gil, M., Wróbel, K., Montewka, J., \& Goerlandt, F. (2020). A bibliometric analysis and systematic review of shipboard Decision Support Systems for accident prevention. Safety Science, 128, 104717. https://doi.org/10.1016/j.ssci.2020.104717

Gillies, R. J., Kinahan, P. E., \& Hricak, H. (2016). Radiomics: Images Are More than Pictures, They Are Data. Radiology, 278(2), 563-577. https://doi.org/10.1148/radiol.2015151169

Guo, Y., Hao, Z., Zhao, S., Gong, J., \& Yang, F. (2020). Artificial Intelligence in Health Care: Bibliometric Analysis. Journal of Medical Internet Research, 22(7), e18228. https://doi.org/10.2196/18228

Gülmez, D., Özteke, İ., \& Gümüş, S. (2021). Overview of Educational Research from Turkey Published in International Journals: A Bibliometric Analysis. Eğitim ve Bilim [Education and Science], 46, 213-239. https://doi.org/10.15390/eb.2020.9317

Haugen, B. R., Alexander, E. K., Bible, K. C., Doherty, G. M., Mandel, S. J., Nikiforov, Y. E., Pacini, F., Randolph, G. W., Sawka, A. M., Schlumberger, M., Schuff, K. G., Sherman, S. I., Sosa, J. A., Steward, D. L., Tuttle, R. M., \& Wartofsky, L. (2016). 2015 American Thyroid Association Management Guidelines for Adult Patients with Thyroid Nodules and Differentiated Thyroid Cancer: The American Thyroid Association Guidelines Task Force on Thyroid Nodules and Differentiated Thyroid Cancer. Thyroid: Official Journal of the American Thyroid Association, 26(1), 1-133. https://doi.org/10.1089/thy.2015.0020

Hu, Y., Yu, Z., Cheng, X., Luo, Y., \& Wen, C. (2020). A bibliometric analysis and visualization of medical data mining research. Medicine, 99(22), e20338. https://doi.org/10.1097/md.0000000000020338

Jalali, M. S., Razak, S., Gordon, W., Perakslis, E., \& Madnick, S. (2019). Health Care and Cybersecurity: Bibliometric Analysis of the Literature. Journal of Medical Internet Research, 21(2), e12644. https://doi.org/10.2196/12644

Jellinger, P. S., Handelsman, Y., Rosenblit, P. D., Bloomgarden, Z. T., Fonseca, V. A., Garber, A. J., Grunberger, G., Guerin, C. K., Bell, D. S. H., Mechanick, J. I., Pessah-Pollack, R., Wyne, K., Smith, D., Brinton, E. A., Fazio, S., \& Davidson, M. (2017). American Association of Clinical Endocrinologists and American College of Endocrinology guidelines for management of dyslipidemia and prevention of cardiovascular disease. Endocrine Practice, 23(Supplement 2), 1-87. https://doi.org/10.4158/ep171764.appgl

Kermany, D. S., Goldbaum, M., Cai, W., Valentim, C. C. S., Liang, H., Baxter, S. L., McKeown, A., Yang, G., Wu, X., Yan, F., Dong, J., Prasadha, M. K., Pei, J., Ting, M. Y. L., Zhu, J., Li, C., Hewett, S., Dong, J., Ziyar, I., \& Shi, A. (2018). 
Identifying Medical Diagnoses and Treatable Diseases by Image-Based Deep Learning. Cell, 172(5), 1122-1131.e9. https://doi.org/10.1016/i.cell.2018.02.010

Kitsios, F., Kamariotou, M., \& Talias, M. A. (2020). Corporate Sustainability Strategies and Decision Support Methods: A Bibliometric Analysis. Sustainability, 12(2), 521. https://doi.org/10.3390/su12020521

Li, J., \& Hale, A. (2016). Output distributions and topic maps of safety related journals. Safety Science, 82, $236-244$. https://doi.org/10.1016/j.ssci.2015.09.004

McCrindle, B. W., Rowley, A. H., Newburger, J. W., Burns, J. C., Bolger, A. F., Gewitz, M., Baker, A. L., Jackson, M. A., Takahashi, M., Shah, P. B., Kobayashi, T., Wu, M.-H., Saji, T. T., \& Pahl, E. (2017). Diagnosis, Treatment, and LongTerm Management of Kawasaki Disease: A Scientific Statement for Health Professionals from the American Heart Association. Circulation, 135(17). https://doi.org/10.1161/cir.0000000000000484

Merigó, J. M., \& Yang, J.-B. (2017). A bibliometric analysis of operations research and management science. Omega, 73, 3748. https://doi.org/10.1016/j.omega.2016.12.004

Minhas, M. R., \& Potdar, V. (2020). Decision Support Systems in Construction: A Bibliometric Analysis. Buildings, $10(6), 108$. https://doi.org/10.3390/buildings 10060108

Miotto, R., Li, L., Kidd, B. A., \& Dudley, J. T. (2016). Deep Patient: An Unsupervised Representation to Predict the Future of Patients from the Electronic Health Records. Scientific Reports, 6(1). https://doi.org/10.1038/srep26094

Nadri, H., Rahimi, B., Timpka, T., \& Sedghi, S. (2017). The Top 100 Articles in the Medical Informatics: a Bibliometric Analysis. Journal of Medical Systems, 41(10), 150. https://doi.org/10.1007/s10916-017-0794-4

Özata, M., \& Aslan, Ş. (2004). Klinik karar destek sistemleri ve örnek uygulamalar [Clinical Decision Support Systems and Model Applications]. Kocatepe Tıp Dergisi [Medical Journal of Kocatepe], 5(1), 11-17.

Park, K., Tan, E.-H., O’Byrne, K., Zhang, L., Boyer, M., Mok, T., Hirsh, V., Yang, J. C.-H., Lee, K. H., Lu, S., Shi, Y., Kim, S.-W., Laskin, J., Kim, D.-W., Arvis, C. D., Kölbeck, K., Laurie, S. A., Tsai, C.-M., Shahidi, M., \& Kim, M. (2016). Afatinib versus gefitinib as first-line treatment of patients with EGFR mutation-positive non-small-cell lung cancer (LUXLung 7): a phase 2B, open-label, randomised controlled trial. The Lancet Oncology, 17(5), 577-589. https://doi.org/10.1016/s1470-2045(16)30033-x

Puzanov, I., Diab, A., Abdallah, K., Bingham, C. O., Brogdon, C., Dadu, R., Hamad, L., Kim, S., Lacouture, M. E., LeBoeuf, N. R., Lenihan, D., Onofrei, C., Shannon, V., Sharma, R., Silk, A. W., Skondra, D., Suarez-Almazor, M. E., Wang, Y., Wiley, K., \& Kaufman, H. L. (2017). Managing toxicities associated with immune checkpoint inhibitors: consensus recommendations from the Society for Immunotherapy of Cancer (SITC) Toxicity Management Working Group. Journal for Immunotherapy of Cancer, 5(1), 95. https://doi.org/10.1186/s40425-017-0300-z

Santos, B. S., Steiner, M. T. A., Fenerich, A. T., \& Lima, R. H. P. (2019). Data mining and machine learning techniques applied to public health problems: A bibliometric analysis from 2009 to 2018 . Computers \& Industrial Engineering, 138, 106120. https://doi.org/10.1016/j.cie.2019.106120

Saqr, M., Ng, K., Oyelere, S. sunday, \& Tedre, M. (2021). People, Ideas, Milestones: A Scientometric Study of Computational Thinking. ACM Transactions on Computing Education, 21(3), 1-17. https://doi.org/10.1145/3445984

Sweileh, W. M., Al-Jabi, S. W., AbuTaha, A. S., Zyoud, S. H., Anayah, F. M. A., \& Sawalha, A. F. (2017). Bibliometric analysis of worldwide scientific literature in mobile - health: 2006-2016. BMC Medical Informatics and Decision Making, 17(1). https://doi.org/10.1186/s12911-017-0476-7

van Nunen, K., Li, J., Reniers, G., \& Ponnet, K. (2018). Bibliometric analysis of safety culture research. Safety Science, 108, 248-258. https://doi.org/10.1016/j.ssci.2017.08.011

Wright, A., Sittig, D. F., Ash, J. S., Feblowitz, J., Meltzer, S., McMullen, C., Guappone, K., Carpenter, J., Richardson, J., Simonaitis, L., Evans, R. S., Nichol, W. P., \& Middleton, B. (2011). Development and evaluation of a comprehensive clinical decision support taxonomy: comparison of front-end tools in commercial and internally developed electronic health record systems. Journal of the American Medical Informatics Association, 18(3), 232-242. https://doi.org/10.1136/amiajnl2011-000113

Yıldız, C. Ç., Başıbüyük, M., \& Yıldırım, D. (2020). Klinik Karar Destek Sistemlerinin Hemşirelikte Kullanımı [The Use of Clinical Decision Support Systems in Nursing]. Inönü Üniversitesi Sağlık Hizmetleri Meslek Yüksek Okulu Dergisi [Journal of Inonu University Health Services Vocational School], 8(2), 483-495. https://doi.org/10.33715/inonusaglik.743296

Yılmaz, A. A., \& Ozdemir, L. (2017). Development and Implementation of the Clinical Decision Support System for Patients with Cancer and Nurses' Experiences Regarding the System. International Journal of Nursing Knowledge, 28(1), 4-12. https://doi.org/10.1111/2047-3095.12099

Editorial record: The article has been peer-reviewed. First submission received on 2 April 2021. Revisions received on 23 April 2021 and 30 April 2021. Accepted for publication on 2 May 2021. The editor in charge of coordinating the peer-review of this manuscript and approving it for publication was Zdenek Smutny (D).

Acta Informatica Pragensia is published by Prague University of Economics and Business, Czech Republic.

ISSN: 1805-4951 